\title{
Health Risks Associated with Long-Term Finasteride and Dutasteride Use: It's Time to Sound the Alarm
}

\author{
Abdulmaged M. Traish (iD \\ Department of Urology, Boston University School of Medicine, Boston, MA, USA
}

\begin{abstract}
$5 \alpha$-dihydrotestosterone ( $5 \alpha$-DHT) is the most potent natural androgen. $5 \alpha$-DHT elicits a multitude of physiological actions, in a host of tissues, including prostate, seminal vesicles, hair follicles, skin, kidney, and lacrimal and meibomian glands. However, the physiological role of $5 \alpha$-DHT in human physiology, remains questionable and, at best, poorly appreciated. Recent emerging literature supports a role for $5 \alpha$-DHT in the physiological function of liver, pancreatic $\beta$-cell function and survival, ocular function and prevention of dry eye disease and kidney physiological function. Thus, inhibition of $5 \alpha$-reductases with finasteride or dutasteride to reduce $5 \alpha$-DHT biosynthesis in the course of treatment of benign prostatic hyperplasia (BPH) or male pattern hair loss, known as androgenetic alopecia (AGA) my induces a novel form of tissue specific androgen deficiency and contributes to a host of pathophysiological conditions, that are yet to be fully recognized. Here, we advance the concept that blockade of $5 \alpha$-reductases by finasteride or dutasteride in a mechanism-based, irreversible, inhabitation of $5 \alpha$-DHT biosynthesis results in a novel state of androgen deficiency, independent of circulating testosterone levels. Finasteride and dutasteride are frequently prescribed for long-term treatment of lower urinary tract symptoms in men with BPH and in men with AGA. This treatment may result in development of non-alcoholic fatty liver diseases (NAFLD), insulin resistance (IR), type 2 diabetes (T2DM), dry eye disease, potential kidney dysfunction, among other metabolic dysfunctions. We suggest that long-term use of finasteride and dutasteride may be associated with health risks including NAFLD, IR, T2DM, dry eye disease and potential kidney disease.
\end{abstract}

Keywords: Diabetes mellitus; Dry eye syndromes; Hypogonadism; Kidney diseases; Non-alcoholic fatty liver disease; 5-alpha reductase inhibitors

This is an Open Access article distributed under the terms of the Creative Commons Attribution Non-Commercial License (http://creativecommons.org/licenses/by-nc/4.0) which permits unrestricted non-commercial use, distribution, and reproduction in any medium, provided the original work is properly cited.

\section{INTRODUCTION}

$5 \alpha$-reductases ( $5 \alpha-\mathrm{Rs})$, a family of several isozymes, play an important role in human physiology by regulating cellular metabolism of androgens, glucocorticoids and other steroids. $5 \alpha-$ Rs are the rate limiting step in the biosynthesis of neuroactive steroids which are critical for central nervous system function [1,2]. $5 \alpha-\mathrm{Rs}_{\mathrm{s}}$ isozymes are widely expressed in many tissues and organs [3]. Metabolites produced by $5 \alpha-$ Rs enzymatic catalysis modulate physiological functions in peripheral and central nervous tissues [1-7]. Finasteride and dutas-

Received: Jan 14, 2020 Revised: Jan 29, 2020 Accepted: Jan 30, 2020 Published online Mar 20, 2020

Correspondence to: Abdulmaged M. Traish iD https://orcid.org/0000-0003-3850-0329

Department of Urology, Boston University School of Medicine, Building A Room 502, 72 East Newton Street, Boston, MA 02118, USA.

Tel: +1-617-358-7561, E-mail: atraish@bu.edu 
teride are synthetic $5 \alpha-$ Rs mechanism-based inhibitors

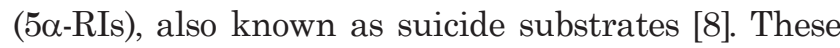
synthetic drugs are widely prescribed to treat men with benign prostatic hyperplasia $(\mathrm{BPH})$ and young men with pattern hair loss, also known as androgenetic alopecia (AGA) [7]. Although these drugs were purported to be "tolerable and safe", their potential for causing long-lasting pathophysiological harm has yet to be fully ascertained [2,7,9,10].

It is important to note that almost none of the clinical trials on finasteride or dutasteride have incorporated in their primary or secondary end-points sensitive measures for insulin resistance (IR), type 2 diabetes (T2DM), lipid accumulation in liver or measures of ocular or kidney dysfunctions. Concerns regarding possible adverse metabolic consequences of $5 \alpha$-Rs inhibition (finasteride and dutasteride) are particularly important given the long-term nature of treatment and the age of patients affected, in whom risk factors for metabolic syndrome are most prevalent.

Androgens and glucocorticoids modulate mitochondrial function, carbohydrate, protein and lipid metabolism and energy balance. Inhibition of androgens and glucocorticoid transformation to their various metabolites may result in pathophysiological states, such as liver diseases, hyperglycemia, hyperlipidemia, IR, and T2DM. We have advanced the hypothesis that irreversible inhibition of $5 \alpha$-Rs by finasteride or dutasteride may interfere not only with the metabolism and clearance of androgens and glucocorticoids but also impedes downstream signaling of androgens and glucocorticoids via their downstream receptor signaling and therefore adversely affect cellular metabolic function [4]. Finasteride and dutasteride irreversibly inhibit the action of $5 \alpha$-Rs [8] resulting in reduction in clearance rates of glucocorticoids and mineralocorticoids and alterations in metabolic function [4,11]. This alteration in androgen and glucocorticoids metabolism potentiates lipid dysregulation and fat accumulation in liver and promotes IR and onset of T2DM [12-17].

In this review we summarize the reported findings related to finasteride and dutasteride on metabolic adverse effects in liver, muscle, kidney and ocular system [12-23]. Adverse effects pertaining to sexual dysfunction, depression and suicidal ideation are discussed in previous reviews [2,7]. Here we will focus on the finding form pre-clinical and clinical studies on the metabolic adverse effects of finasteride and dutasteride and highlight the potential health related risks of these drugs.

\section{Finasteride and dutasteride induce liver lipid accumulation and steatosis}

Dowman et al [14] reported that $5 \alpha$-Rs types 1 and 2 are highly expressed in human liver and inhibition of these enzymes may elicit adverse metabolic consequences. In the animal model, inhibition of $5 \alpha-R s$ types 1 and 2 impeded glucocorticoids and androgens metabolism and contributed to the pathogenesis of nonalcoholic fatty liver disease (NAFLD) [13,14]. $5 \alpha-\mathrm{R}$ type 1 knockout mice $(\alpha-\mathrm{R} 1 \mathrm{KO})$, which were fed high-fat diet, exhibited increased susceptibility to metabolic dysfunction and liver fibrosis [13]. Furthermore, deficiency in $5 \alpha-R$ type 1 in the animal model predisposed susceptibility to glucose intolerance and hyperinsulinemia [13]. More importantly, finasteride treatment of intact or castrated male obese Zucker rats also induced hyperinsulinemia and hepatic steatosis [13]. More importantly, animals with $5 \alpha-\mathrm{R}$ type 1 deficiency exhibited fat accumulation in the liver, which was attributed to impairment of enzymes involved in fatty acid-oxidation and gluconeogenesis, concomitant with increased enzymatic activities involved in triglyceride esterification and cholesterol synthesis and excretion [13]. These findings suggest that 5-R type 1 deficiency or inhibition of 5-R type 1 activity induces IR and hepatic steatosis, consistent with the intrahepatic accumulation of glucocorticoids, which predisposes to hepatic fibrosis. Pharmacological inhibition of $5 \alpha-R s$ by finasteride or dutasteride augmented cortisol action in liver, which modulated hepatic lipid flux. These observations may have significant clinical implications in patients prescribed finasteride or dutasteride therapy for long-term durations [11].

In a recent study by Mak et al [15], animals fed high fat diet (HFD) and treated with dutasteride exhibited exacerbated adverse metabolic phenotype and increased hepatic triglyceride levels. Furthermore, animals fed "American lifestyle induced obesity syndrome" diet exhibited higher incidence of hepatic steatosis and reduced expression of genes involved in insulin signaling, as compared with wild type animals [14]. These findings suggest that reduced $5 \alpha$-dihydrotestosterone (5 $\alpha$-DHT) levels, concomitant with decreased glucocorticoids clearance, may contribute to increased steatosis in mice with $5 \alpha-R$ type 1 deficiency. In addition, Zhang et al [24] reported that, in rat liver, $5 \alpha$-DHT reduces 
lipid accumulation and cholesterol synthesis via increasing expression of carnitine palmitotyltransferase1 and phosphorylation of 3-hydroxy-3-methyl-glutarylCoA reductase. These findings support the contention that $5 \alpha$-Rs play an important role in regulating liver fat metabolism.

In men, inhibition of $5 \alpha-R$ types 1 and 2 with dutasteride resulted in hepatic IR, hepatic lipid accumulation, and decreased adipose lipid mobilization, without impacting peripheral insulin sensitivity [12,16]. Insulinregulated metabolites levels changed significantly in response to finasteride or dutasteride treatments. These findings suggest that $5 \alpha-\mathrm{R}$ types 1 and 2 deficiencies or their pharmacological inhibition by finasteride or dutasteride contribute to IR and hepatic steatosis. In a population-based study, men with fatty livers had reduced relative excretion of $5 \alpha$-reduced cortisol metabolites, resulting in liver fat accumulation [25]. Furthermore, protein expression of $5 \alpha-\mathrm{R}$ types 1 in human liver correlates with features of steatohepatitis [14].

\section{Finasteride and dutasteride induce insulin resistance and type 2 diabetes}

Upreti et al [16] demonstrated that men receiving dutasteride exhibited decreased rate of glucose disposal during high-dose insulin infusion concomitant with increased fasting plasma C-peptide and homeostatic model assessment of IR and increased plasma insulin levels, when tracers were infused alone. In humans receiving dutasteride, impaired insulin sensitivity in peripheral organs, including skeletal muscle and/or adipose tissue were recorded. The authors suggested that the adverse changes in IR may, in part, be mediated by impaired glucose disposal, mainly in muscle where $5 \alpha-R$ types 1 is expressed [16]. In a retrospective registry study, Traish et al [6] reported on a cohort of 230 men aged between 47 and 68 years (mean age $=57.78 \pm 4.81$ years) who were treated with dutasteride $(0.5 \mathrm{mg} / \mathrm{d})$ for lower urinary tract symptoms (LUTS), secondary to BPH and patients were followed-up for 36 to 42 months. Dutasteride resulted in increased blood glucose, glycosylated hemoglobin A, total cholesterol, and low-density lipoprotein cholesterol levels. In addition, dutasteride treatment increased activities of liver alanine aminotransferase and aspartate aminotransferase, suggesting dysregulation of liver metabolism. These observations suggest that long-term dutasteride therapy induced imbalance in metabolic function.
Most recently, Wei et al [17] investigated the incidence of new onset T2DM in men receiving dutasteride or finasteride for long-term treatment of $\mathrm{BPH}$, utilizing the UK Clinical Practice Research Datalink and Taiwanese National Health Insurance Research Database. New onset of T2DM events was recorded during a mean followup time of $5.2 \pm 3.1$ years. There was a modest increased risk of T2DM for dutasteride and finasteride compared with tamsulosin. As shown in Fig. 1, the risk of developing T2DM was higher for patients receiving dutasteride or finasteride compared with tamsulosin (adjusted hazard ratio $[\mathrm{HR}]=1.34,95 \%$ confidence interval $[\mathrm{CT}]=1.17$ to 1.54 ; and $1.49,1.38$ to 1.61 , respectively), but the risk for dutasteride and finasteride did not differ (0.90, 0.77 to 1.06) [17]. The authors concluded that the risk of developing new onset T2DM appears to be higher in men with $\mathrm{BPH}$ exposed to $5 \alpha$-RIs (finasteride or dutasteride) as compared with men receiving tamsulosin. Interestingly, Lee et al [26] reported in a nation-wide population-based study of newly diagnosed patients with BPH, who were treated with $5 \alpha$-RIs and compared with subjects who were not treated with $5 \alpha$-RIs and were followed for 5 years, lower cumulative rate of T2DM was noted in the treatment group compared to the control group. These findings are in stark contrast to those reported by Wei et al [17].

\section{Finasteride and dutasteride impair ocular function and cause development of dry eye disease}

Androgen deficiency produces pathophysiological changes manifested in reduction of tear production and evaporative dry eye conditions [27-32]. Meibomian gland disease and altered lipid patterns in meibomian gland secretions were observed in women with complete androgen insensitivity syndrome [33]. Finasteride administration significantly downregulated androgen receptors (ARs) in the lacrimal gland the significance observed with tear film break up time (TBUT) and tear flow could be attributed to the lack of $5 \alpha$-DHT in the lacrimal glands [20,23]. Finasteride treated female rats showed $49 \%$ of significant reduction in tear flow at the end of the 10th day. There was a considerable $29 \%$ significant TBUT reduction observed in female rats. Finasteride treated male rats showed significant $40 \%$ and $63 \%$ reductions for tear flow and TBUT, respectively.

Zhang et al [19] and Li et al [23] described the effects 


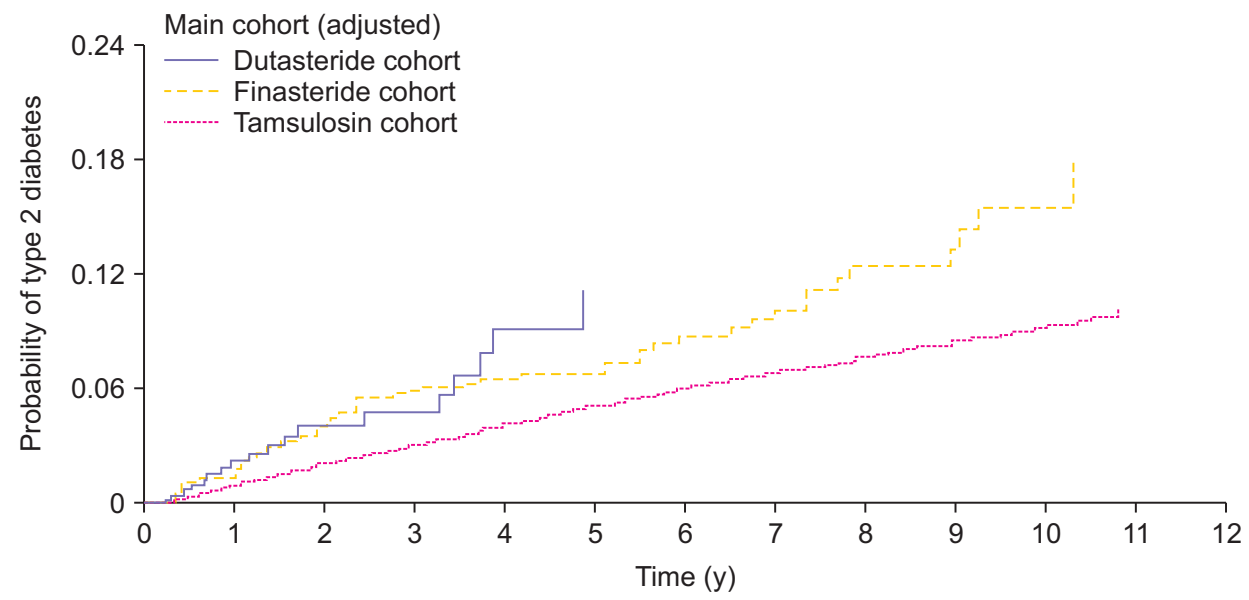

No. at risk

\begin{tabular}{|c|c|c|c|c|c|c|c|c|c|c|c|}
\hline \multicolumn{12}{|c|}{ Dutasteride cohort } \\
\hline 1,251 & 395 & 226 & 143 & 92 & 60 & 29 & 9 & 4 & 0 & 0 & 0 \\
\hline \multicolumn{12}{|c|}{ Finasteride cohort } \\
\hline 2,445 & 1,492 & 962 & 659 & 469 & 353 & 281 & 213 & 167 & 104 & 66 & 34 \\
\hline \multicolumn{12}{|c|}{ Tamsulosin cohort } \\
\hline 86,263 & 30,545 & 20,566 & 14,748 & 10,645 & 7,530 & 5,315 & 3,652 & 2438 & 1597 & 899 & 410 \\
\hline
\end{tabular}

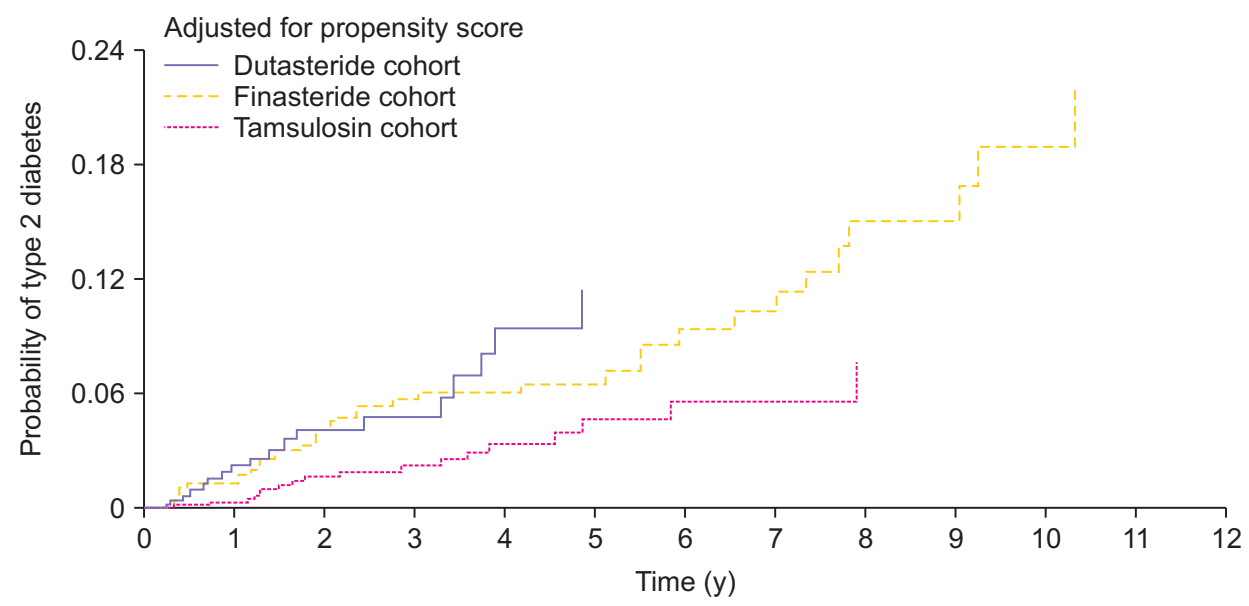

No. at risk

Dutasteride cohort

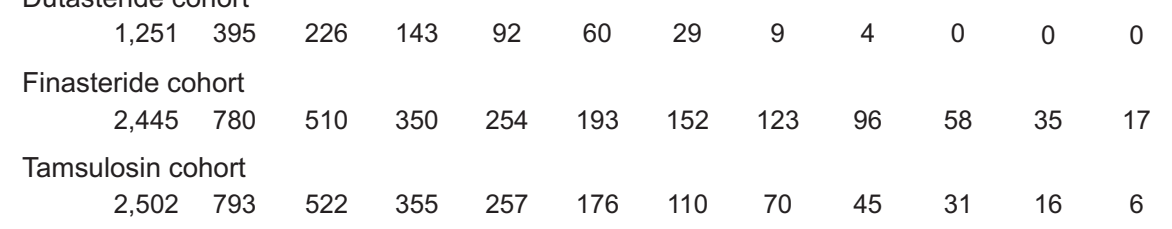

Fig. 1. Cumulative incidence of type 2 diabetes mellitus in Taiwanese National Health Insurance Research Database cohort over study period: main cohort (adjusted) and adjusted for propensity score. Data from Wei et al (BMJ 2019;365:I1204) [17]. of $5 \alpha$-DHT inhibition by finasteride on 'lacrimal gland histopathology' and 'ocular function'. Finasteride administration effectively induced dry eye in rats by 14 days after administration. Finasteride treated rats had significantly higher fluorescein staining scores and lower aqueous tear quantity and TBUT as compared with control rats Finasteride significantly diminished tear flow and resulted in severe inflammation of the lacrimal gland. Tear secretion was also significantly reduced in finasteride treated animals compared with control animals on days 14, 21, and 28 . As reported by Zhang et al [19], the TBUT value of finasteride treated animals were markedly decreased after finasteride treatment, with significant differences when compared with the control group on days $7,14,21$, and $28(\mathrm{p}=0.041$, $\mathrm{p}=0.003, \mathrm{p}=0.004$, and $\mathrm{p}=0.002$, respectively) (Fig. 2) [19]. The histopathologic changes of lacrimal glands in animals treated with or without finasteride on day 28 are described in Fig. 3 [19]. In the untreated, control group, Fig. 3A the normal acinar structure was well 
preserved, and no significant lymphocyte infiltration was noted. In contrast, in animals treated with finasteride, a severe inflammatory response was recorded in the lacrimal gland. Significant increase in the number of lymphocytes infiltrating the interlobular space and surrounded the acinar and ductal cells were observed Fig. 3B. These observations suggest that inhibition of testosterone (T) conversion to $5 \alpha$-DHT results in potentiating an inflammatory response that increases the infiltration of lymphocytes into the lacrimal gland.

In patients undergoing antiandrogen treatment, Krenzer et al [34] reported that chronic androgen deficiency was associated with meibomian gland dysfunction and dry eye. Li et al [23] utilized finasteride to induce dry eye disease in animal model and evaluated ocular surface status and inflammatory cytokine gene expression in the lacrimal gland. Most noted was that finasteride induced significant tear deficiency with sig-

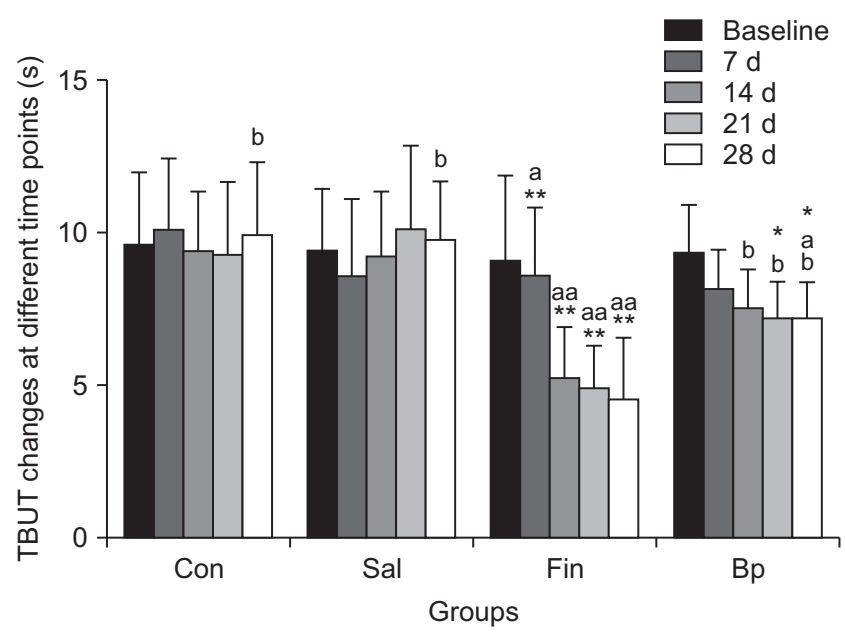

Fig. 2. Tear film break up time (TBUT) changes in the four groups at different time points $\left({ }^{*} p<0.05,{ }^{* *} p<0.01\right.$ vs. baseline within the same group). Con: control, Sal: physiological saline, Fin: oral finasteride, Bp: oral finasteride and Bidens pilosa L. ${ }^{\mathrm{a}} \mathrm{p}<0.05$ within the group Con at the same time point. ${ }^{b} p<0.05$ within the group Fin at the same time point. Data from Zhang et al (Cell Physiol Biochem 2016;39:266-77) [19]. nificant inflammatory cell infiltration in the lacrimal gland. Finasteride treatment increased the expression of B-72, interleukin (IL)-1 $\beta$, IL-4, IL-6, IL-10, matrix metalloproteinase-8, Fas ligand, tumor necrosis factor (TNF)- $\alpha$ and metalloproteinase inhibitor 1 levels in the lacrimal gland of the dry eye model.

\section{Adverse effects of finasteride and dutasteride on kidney function}

The physiology of kidney is mediated by ARs localized in the cells of most parts of the nephron. Thus, androgen deprivation therapy (ADT) or inhibition of androgen metabolism may affect kidney physiological function. Recently, it was shown that finasteride downregulated $\mathrm{AR}$ expression in the cortical region of the kidney [18]. Finasteride treatment resulted in reduction in AR-positive cells in the renal corpuscle $(0.06 \% \pm 0.03 \%)$ as compared with untreated animals $(0.14 \% \pm 0.12 \%)$. Similarly, the percentage of AR-positive cells in the proximal convoluted tubule of finasteride treated animals also demonstrated marked reductions compared with control animals $(0.16 \% \pm 0.17 \%$ vs. $0.69 \% \pm 0.32 \%$, respectively). Furthermore, the percentage of AR-positive cells the distal convoluted tubule (DCT) of finasteridetreated rats was markedly reduced compared to controls $(0.50 \% \pm 0.26 \%$ vs. $0.91 \% \pm 0.12 \%$, respectively) [18]. The decrease of AR expression lead to histopathological changes in the kidney cortex, such as apoptosis (Fig. 4), fibrosis (Fig. 5) and infiltration of mononuclear cells [18]. Finasteride treatment increased glomerulosclerosis, tubulointerstitial fibrosis, and the infiltration of mononuclear cells. The authors postulated that finasteride treatment in mature male animals led to decreased AR expression in kidney cortex and finasteride induced pathomorphological changes (glomerulosclerosis, tubulosclerosis, dysplastic glomeruli, and tubules with lumen dilatation) were associated with the reduced
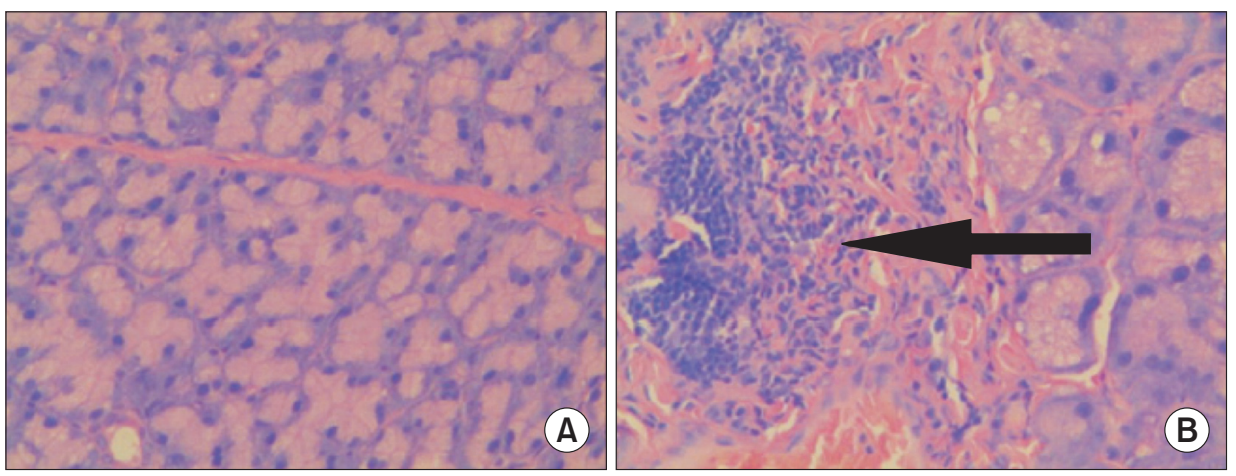

Fig. 3. Lacrimal gland histopathology $(\mathrm{H} \& \mathrm{E}, \times 400)$. (A) Lacrimal gland from the control group; (B) Lacrimal gland from the oral finasteride group. A large number of lymphocytes had infiltrated the interlobular space and surrounded the acinar and ductal cells as indicated by the black arrow. Data from Zhang et al (Cell Physiol Biochem 2016;39:26677) [19] with original copyright holder's permission. 

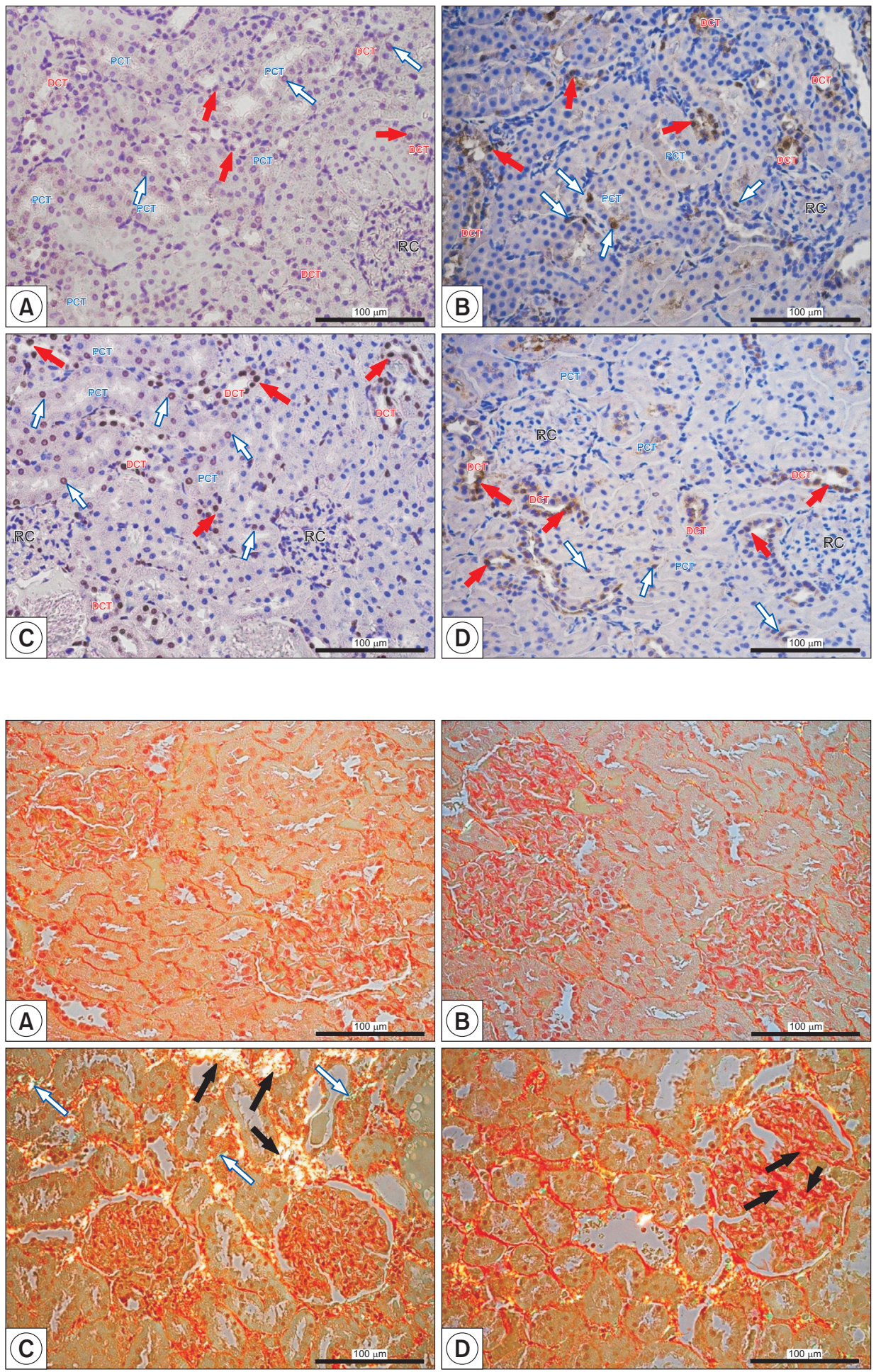

Fig. 4. Representative microphotography showing terminal deoxynucleotidyl transferase dUTP nick end labeling reaction $(A, C)$ and proliferating cell nuclear antigen-positive cells $(B, D)$ in control $(A, B)$ and finasteride-treated $(C, D)$ rats. Red filled arrows indicate positive signaling in nuclei of proximal convoluted tubule (PCT); blue empty arrows indicate positive signaling in nuclei of the distal convoluted tubule (DCT). Slides were rinsed in phosphate buffer saline and labeled with streptavidin conjugated with horseradish peroxidase. To visualize the effect of the reaction (places of DNA split), 3,3'-diaminobenzidine was added. Positive staining was defined microscopically (Leica DM5000B, Germany) through visual identification of brown pigmentation of the cell nucleus. Scale bar from objective magnification $\times 40(A$, $B ; C, D)$ is $100 \mathrm{~mm}$. RC: renal corpuscle. Data from Baig et al (Int J Environ Res Public Health 2019;16:E1726) [18]. expression of intracellular junctional proteins. Finasteride also altered the apoptotic/proliferating ratio of nephron cells and the increased lymphocytes infiltrations into the area of pathologically altered convoluted tubules were accompanied by impaired androgen/estrogen homeostasis.

\section{DISCUSSION}

\section{Inhibition of $5 \alpha$-dihydrotestosterone} biosynthesis induces a novel form of androgen deficiency independent of testosterone levels

$\mathrm{T}$ is synthesized and secreted by the testis and circulates in plasma as free (unbound) $\mathrm{T}$ or bound to sex 
hormone binding globulin and serum albumin. The unbound fraction of T, known as biologically available free $\mathrm{T}$, enters target and nontarget cells by passive diffusion through the phospholipid plasma membrane (Fig. 6). In androgen target cells, $\mathrm{T}$ is further metabolized to $5 \alpha$-DHT via $5 \alpha$-Rs. In target cells, both T and $5 \alpha$-DHT interact with the AR; however, $5 \alpha$-DHT binds to the AR with approximately 10-fold higher affinity compared with $\mathrm{T}$ [35]. This large difference in the affinity of T and $5 \alpha$-DHT for AR make $5 \alpha$-DHT the critical physiological androgen modulator in many tissues, and therefore, inhibition of its biosynthesis may result in a novel state of androgen deficiency. The wide expression and distribution of $5 \alpha-R s$ in many tissues and organs [2] suggests that although $\mathrm{T}$ is the main circulating androgen, its conversion to the high affinity $5 \alpha$-DHT in many of these tissues is responsible for regulating tissue and cellular metabolism and function. Binding of $5 \alpha$-DHT to AR results in activation and transformation of the AR into a higher affinity complex for DNA and induces its translocation from the cytoplasm to the nucleus where it interacts with the androgen response elements. This high affinity binding to a specific DNA sequences, result in recruitments of AR co-activators or co-repressors, resulting in regulating specific gene expression. This results in changes in cellular metabolism and function.

In addition to the well-recognized role of $5 \alpha$-DHT and not total $\mathrm{T}$ in prostate growth and function, several other examples exist, which illustrate the key physiological role of $5 \alpha-\mathrm{DHT}$ and not total $\mathrm{T}$ in mediating tissues function and metabolism. One such example is the role of $5 \alpha$-DHT in maintaining erectile physiology [36]. It is now well-established that men treated with finasteride or dutasteride for $\mathrm{BPH}$ or AGA experience greater risk of erectile dysfunction, loss of libido and ejaculatory dysfunction [1,7,37-39]. These observations are strongly supported by studies in animal models, which demonstrated that finasteride and dutasteride, by inhibiting biosynthesis of $5 \alpha$-DHT, impair corpus cavernosum growth and trabecular smooth muscle relaxation, endothelial function, increased connective tissue deposition and result in erectile dysfunction, even in the presence of physiological levels of total T [36,40-42]. Erectile dysfunction was attributed to reduction in intracellular $5 \alpha-\mathrm{DHT}$ levels which were deemed essential for maintaining tissue function and metabolism even in the presence of physiological levels of T [43]. In addition, $5 \alpha-\mathrm{DHT}$ is deemed critical for activating gene expression of neuronal and endothelial nitric oxide synthases, which are critical physiological mediators of penile erection [36,40-42]. These findings clearly demonstrate that $5 \alpha-\mathrm{DHT}$ and not total T levels are critical for maintaining erectile physiology. A second example for the critical role of $5 \alpha$-DHT is derived from the studies on fertility. Reduction of spermatogenesis progression is impaired in men lacking $5 \alpha-R$ type 2 isozyme [44], suggesting that $5 \alpha-\mathrm{DHT}$ is critical for spermatogenesis, as well as the structure of seminiferous tubules/spermatocysts and Sertoli cells are affected by loss of $5 \alpha$-DHT, since they Sertoli cells support germ cells' development, and the structure of the

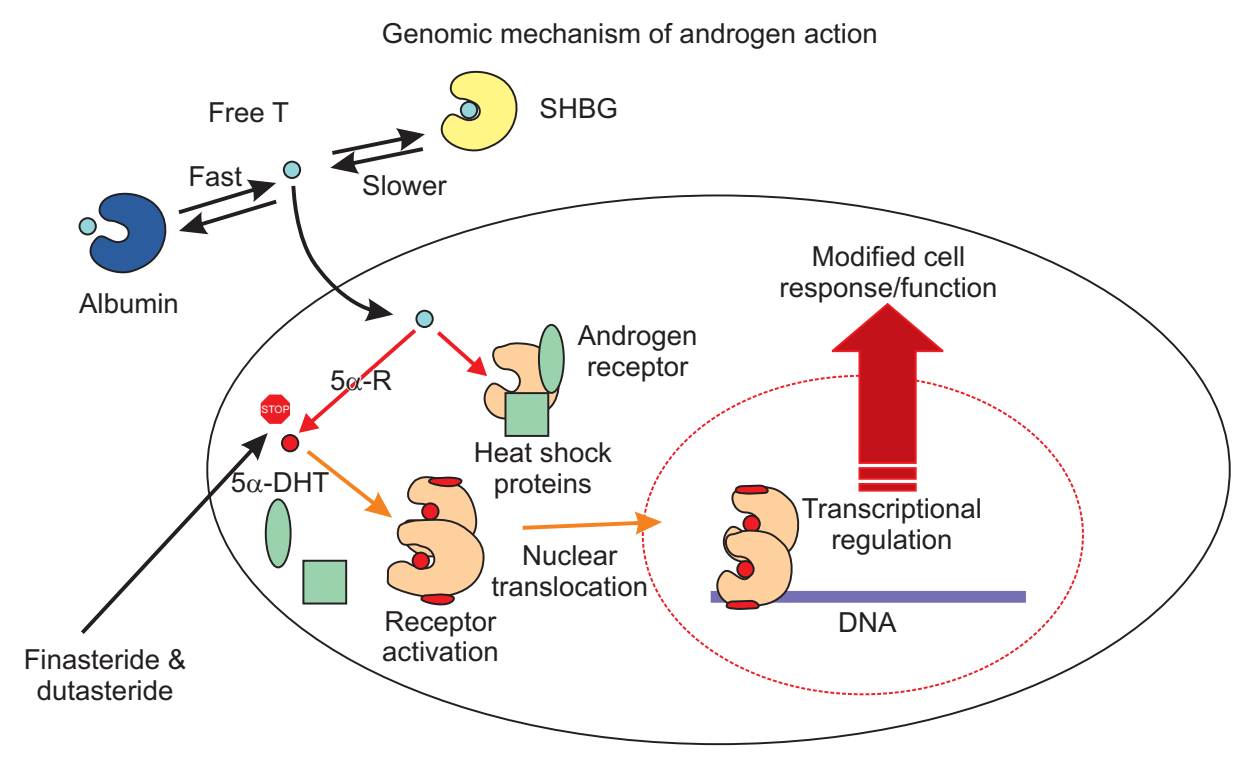

Fig. 6. Universal genomic molecular mechanism of androgen action. One key biochemical reaction in this sequence of pathways is the transformation of testosterone (T) to $5 \alpha$-dihydrotestosterone ( $5 \alpha$-DHT) via $5 \alpha$-reductases ( $5 \alpha-\mathrm{Rs}$ ). This pathway is critical in the function of androgen receptor, since $5 \alpha-\mathrm{DHT}$ is more potent natural ligand than T. SHBG: sex hormone binding globulin. 
seminiferous tubules concomitant with maintenance of the blood-testis barrier $[45,46]$. A third example for the relevance of $5 \alpha-\mathrm{DHT}$ instead of total T is the effects of $5 \alpha$-DHT on scalp hair growth. In absence of $5 \alpha$-DHT baldness pattern was observed in men as determined in men with mutations in the $5 \alpha-\mathrm{R}$ type 2 gene resulting in no expression of 5a-R type 2 enzyme $[44,47]$ even though there were not changes in total $\mathrm{T}$ levels. In the scalp, the presence of $5 \alpha$-DHT induces hair miniaturization by converting terminal hairs into vellus hairs [48-50]. This specific 5 $\alpha$-DHT-mediated biological event prompted the development of finasteride for treatment of AGA [51,52] A fourth example is the recent observations that treatment of animals with finasteride or dutasteride results in dry eye disease within a very short period of time $[19,23]$. This illustrates the role of $5 \alpha-\mathrm{DHT}$ on the lacrimal and meibomian glands structure and function and on the overall ocular function.

To date, the role of $5 \alpha$-DHT in human physiology is not fully appreciated. The role of $5 \alpha$-DHT in growth of the prostate is the one area were an agreement on a role for this potent androgen. However, recent literature supports a role for $5 \alpha$-DHT in liver function [12,1416], $\beta$-cell function [53,54] and in ocular [27] and kidney function [18]. This introduces a new paradigm that, while $\mathrm{T}$ is the most circulating androgen, its derivative, $5 \alpha$-DHT, is the most potent androgen and have a multitude of physiological action that is now being recognized. Therefore, inhibition of $5 \alpha$-DHT biosynthesis by synthetic inhibitors acting via a mechanism-based (irreversible) inhibition of $5 \alpha$-RS (suicide substrates) induce a novel form of tissue specific androgen deficiency and results in pathophysiological conditions that are not fully recognized.

It worth noting that finasteride has been shown to inhibit both $5 \alpha-R$ types 1 and 2 in rat [55], monkey [56] and humans [57]. While the affinity and selectivity of finasteride towards $5 \alpha-\mathrm{R}$ type 2 is far greater than that for $5 \alpha$-R type 1 , the long-term administration of finasteride (5 mg) in $\mathrm{BPH}$ patients and $1 \mathrm{mg}$ in AGA patients would be expected to bring about sufficient drug plasma levels to inhibit of both $5 \alpha-R$ types 1 and 2. In addition, since finasteride and dutasteride act via a mechanism-based inhibition (slow dissociation rate) rendering the reaction nearly irreversible, once bound to the active site, finasteride and dutasteride are tightly bound to the enzyme resulting in inactivation of the enzyme. Furthermore, with the advent use of dutaste- ride which inhibits both types, this drug brings about complete inhibition of both isozymes. Finally, both finasteride and dutasteride are believed to inhibit $5 \alpha-R$ type 3 which is expressed in a host of tissues. Thus, the long-term administration of these drugs may bring about pathophysiological harm in some tissues that has yet to be recognized.

Although many clinical studies claimed that finasteride and dutasteride 'are safe and tolerable' [7], new emerging evidence suggests that finasteride and dutasteride induce metabolic dysfunction, such as hyperglycemia [16], IR [13,16], liver fat accumulation [12,14], liver steatosis and liver fibrosis [12,14], and T2DM [17]. It should be noted that many reported clinical trials failed to incorporate specific measures of metabolic dysfunction (e.g., liver lipid accumulation; hyperglycemia, IR) as primary or secondary end points, in order to evaluate the effects of these drugs on metabolic dysfunction $[9,10]$.

Gild et al [58] identified 82,938 men 66 years old or older who were diagnosed with localized prostate cancer (Surveillance, Epidemiology and End Results; Medicare database from 1992 to 2009). Men with preexisting NAFLD, liver disease, diabetes or metabolic syndrome were excluded from study. Men who underwent ADT were more likely to be diagnosed with NAFLD ( $\mathrm{HR}=1.54,95 \% \mathrm{CI}=1.40-1.68)$, liver cirrhosis ( $\mathrm{HR}=1.35$, 95\% CI $=1.12-1.60$ ), liver necrosis ( $\mathrm{HR}=1.41,95 \% \mathrm{CI}=1.15$ 1.72) and any liver disease (HR=1.47, 95\% $\mathrm{CI}=1.35-1.60)$, as compared to men who remained untreated with ADT. Kim et al [59] showed that men in the low T quintile were at a higher risk for NAFLD than men in the highest serum $\mathrm{T}$ quintile, even after adjusting for age, smoking, diabetes, exercise, body mass index (BMI), triglycerides, and high-density lipoprotein cholesterol (odds ratio [OR] 95\% CI of 5.12 [2.43-10.77]) for NAFLD $(p=0.0004)$. These observations suggested that androgen deficiency is independently associated with NAFLD. In a retrospective observational cross-sectional study in which 248 men with T2DM were enrolled, Miyauchi et al [60] reported that after adjusting for all relevant variables, androgen deficiency was inversely associated with liver fibrosis. These findings strongly suggest that androgen deficiency contributes to liver disease.

In liver, androgens upregulate insulin receptor expression and activity and increase glycogen synthesis and cholesterol synthesis and uptake [61]. Androgens suppress lipogenesis, glucose uptake and cholesterol 
removal in liver [62]. Androgens were shown to attenuate development of hepatic steatosis [62,63]. Androgen deficiency was shown to be associated with NAFLD. This pathology is a major metabolic complication and represents a spectrum of pathologies that encompass intra-hepatic accumulation of triglycerides, steatosis, diffuse tissue inflammation or non-alcoholic steatohepatitis, which may progress to advanced hepatic fibrosis and cirrhosis [64]. Androgen deficiency (low serum $\mathrm{T}$ levels) was reported to be independently associated with NAFLD as well as an inverse association between serum $\mathrm{T}$ and hepatic steatosis [59,65]. In testicular feminized mice, HFD induced increased hepatic lipid deposition [66] and liver steatosis and IR most likely via upregulation of hepatic expression of sterol regulatory element-binding protein (SREBP)-1c, acetylCoA carboxylase [ACC], and peroxisome proliferatoractivated receptor (PPAR)- $\gamma$ to increase lipid synthesis and downregulation of PPAR $\alpha$ to decrease fatty acid oxidation. In AR knock-out mice models, introduction of HFD resulted in development of hepatic steatosis and IR, suggesting loss of AR function alters lipid metabolism in liver [67,68]. In experimental animal models, orchiectomy resulted in development of NAFLD and IR concomitant with hyperlipidemia, accumulation of hepatic triglycerides and cholesterol, hyperglycemia and hyperinsulinemia and impaired oral glucose tolerance test and insulin tolerance test [69]. Furthermore, orchiectomy resulted in stimulation of hepatic fatty acids oxidation via activation of PPAR $\alpha$, and accumulation of hepatic triglycerides and cholesterol due to upregulation of hepatic SREBP-1, SREBP-2 and activation of ACC-1, mediated by the inhibition the adenosine monophosphate-activated protein kinase $\alpha-1$ activity. More importantly, these metabolic alterations were reversed and ameliorated by $\mathrm{T}$ treatment of orchiectomized animals. Similarly, in animal models of $5 \alpha$-reductase knockout, HFD induced upregulation of expression of genes involved in lipid storage and downregulate genes for fatty acid oxidation concomitant with accumulate lipid in their livers [14]. The role of $5 \alpha$-DHT in liver function is further supported by studies in which finasteride treatment of male obese Zucker rats induced liver steatosis [13]. Therefore, $5 \alpha$-reductase play a key role in androgen metabolism and are critical to prevention of liver steatosis. These observations suggest that $5 \alpha-\mathrm{DHT}$ is critical in liver metabolism and function.

Zitzmann [70] suggested that androgen deficiency in men is a major risk factor for the development of metabolic syndrome and T2DM. Also, Traish et al [71] reviewed the role of androgen deficiency in promoting IR and diabetes and suggested that androgen deficiency may contribute to onset of diabetes. In prostate cancer patients treated with AR blockers or with ADT exhibited higher incidence of T2DM [72]. Furthermore, AR-deficient male mice exhibit IR and obesity [67,68]. Studies in animal models suggested that androgen treatment protects $\beta$-cells from apoptotic damage as well as stimulate insulin production and secretion [73,74]. Recently, Navarro et al [53] and Mauvais-Jarvis [54] demonstrated that androgens act directly on b cells and regulate insulin secretion in males and androgens enhance glucose stimulated insulin secretion in a physiological manner. Loss of AR action in $\beta$-cells produces insulin deficiency, which predisposes to diabetes. These findings strongly suggest that androgen deficiency predisposes to $\beta$-cell dysfunction and failure in men and contributes to IR and diabetes.

Traish et al [4] have advanced the hypothesis that inhibition of $5 \alpha-R_{\mathrm{s}}$ by finasteride and dutasteride alters not only androgens metabolism but also alters glucocorticoids, mineralocorticoids and progestins metabolism and may interfere with downstream receptor actions and signaling of these steroid hormones. The authors suggested that finasteride and dutasteride inhibit $5 \alpha-R_{s}$ activities and reduce the clearance of glucocorticoids and mineralocorticoids, potentiating IR, diabetes and vascular disease. Mak et al [15] suggested that hepatic glucocorticoid excess may underlie the mechanism of the adverse metabolic changes observed after $5 \alpha-\mathrm{R}$ type 1 inhibition or disruption, driving hepatic steatosis and $\mathbb{R}$. The authors proposed that inhibition of $5 \alpha-R s$ types 1 and 2 may increase the circulating glucocorticoids and in turn increase hepatic glucocorticoid receptor activation resulting in the adverse metabolic phenotype observed after pharmacological inhibition and a contributory role after genetic disruption of $5 \alpha-R$ type 1 .

Traish et al [75] have advanced a framework by which androgens modulate mitochondrial function. In this schema, the authors suggested that androgens increase the expression of PPAR $\gamma$ coactivator $1 \alpha$, which in turn increases mitochondrial transcription factor A (Tfam) expression as well as mitochondrial biogenesis. The increase in mitochondrial biogenesis increases levels of nuclear respiratory factor 1, which in turn in- 
creases oxidative phosphorylation. Androgens increase Tfam expression as well as serine-threonine kinase (Akt) phosphorylation, both of which decrease apoptosis leading to an increase in oxidative phosphorylation. Androgens stimulate lipolysis and down-regulates lipoprotein lipase activity and increases expression of fatty acid-binding protein leading to an increase in fatty acid oxidation and in oxidative phosphorylation. Androgens increase expression of pyruvate dehydrogenase, which increases production of oxaloacetate and acetyl-CoA leading to a stimulation of the tricarboxylic acid cycle (TCA). Androgens also increase expression of succinate dehydrogenase and aconitase, also upregulating TCA and increasing oxidative phosphorylation. Finally, androgens increase the expression of cytochrome c oxidase, which leads to an increase in oxidative phosphorylation. The increase in oxidative phosphorylation leads to a decrease in reactive oxygen species and an increase in insulin sensitivity. Yialamas et al [76] have demonstrated that acute androgen withdrawal reduces insulin sensitivity in young healthy men with idiopathic hypogonadotropic hypogonadism. The acuity $\mathrm{T}$ deficiency and absence of changes in BMI or leptin levels suggest that androgens modulate insulin sensitivity in the absence of apparent or detectable changes in body composition. Pitteloud et al [77,78] demonstrated that low $\mathrm{T}$ levels were associated with an adverse metabolic profile and proposed a novel unifying mechanism that low $\mathrm{T}$ levels impair mitochondrial function and promote IR. T deficiency may promote IR by altering fatty acid metabolism and reduced expression of genes involved in oxidative metabolism [75].

Krenzer et al [34] demonstrated that ADT with leuprolide acetate and goserelin acetate, and anti-androgen treatment with the AR blockers bicalutamide and flutamide or inhibition of 5-reductase transformation of $\mathrm{T}$ to $5 \alpha$-DHT, by finasteride or dutasteride, resulted in meibomian gland dysfunction concomitant with tear film instability and significant increase in tear film debris and an abnormal tear film meniscus resulting in functional dry eye. Most importantly, ADT, AR blockade or inhibition of T conversion to $5 \alpha$-DHT, all produced significant alterations in lipids secretions in the meibomian gland [20,23,27]. Sullivan et al [27] have reported that $5 \alpha$-DHT regulates expression of almost 3,000 genes in immortalized human meibomian gland epithelial cells (IHMGECs) and $5 \alpha$-DHT regulates lipidand keratin-related genes. Reduced TBUT in mice after orchiectomy were largely resolved following $5 \alpha$-DHT treatment.

Meibomian and the accessory lacrimal glands secret lipids that forms the lipid layer which acts as a lubricant to prevent evaporation and provides film stabilization [27]. The lacrimal gland and the accessory lacrimal gland contribute to the aqueous layer which is comprised of electrolytes, proteins, and immunoglobulins among others. This aqueous layer is critical for lubrication, antimicrobial activity and mechanical clearance. The conjunctival goblet cells and epithelial cells synthesize and secrete sulphomucins, sialomucin complexes and several glycoproteins known as mucins. These glycoproteins reduce the surface tension and contribute to stabilization of the aqueous layer. Tear film is a fluid secreted to protect the ocular surface from chemical, physical and microbial insults. Tear film structure is encompassing an anterior lipid layer that provides stability via interaction with the mucin aqueous phase. Tear film serves as a lubricant and a refractive surface of the eye. Tear film exhibits a complex biochemical and biophysical composition and is very dynamic, so it maintains visual homeostasis. The various components of tear film interact to form a cohesive lubricant gel. Several factors contribute to tear film instability and loss of functional integrity and its degradation or removal. These include nasal derange, evaporation and conjunctiva absorption and loss of lipid biosynthesis or glycoproteins by the meibomian gland and lacrimal glands. It is important to point out that human corneal epithelial, stromal and endothelial cells express AR, in addition to progesterone and estrogen receptors suggesting a role for these hormones in cornea physiological function $[79,80]$.

A host of potential mechanisms were proposed on how androgens may affect ocular function. Among these are the anti-inflammatory function of androgens via attenuating $\mathrm{L}-1$ and TNF-expression and synthesis; thus, maintaining the function of the lachrymal gland [81]. In addition, androgens regulate the synthesis and secretion of lipids by the meibomian gland which is critical for lubricating the ocular surface and reducing evaporation of the aqueous component [27-32]. Furthermore, androgens maintain the structural and functional integrity of the lacrimal gland and meibomian glands, thus maintaining tear film production and its stability. Androgens regulate the expression of genes related to lipid and sterol biosynthesis and fatty acid 
metabolism, lipid and protein transport and intracellular vesicles trafficking [82].

Mucin 1 is aglycoprotein with extensive O-linked glycosylation of its extracellular domain which lines the apical surface of epithelial cells in eyes and plays a critical role in maintaining the stability of the tear film [83-86]. Recently it has been reported that $5 \alpha-\mathrm{DHT}$ upregulates the expression of MUC1 in an AR-dependent manner [87]. Furthermore, androgen deficiency induced by gonadotropin-releasing hormone treatment, anti-androgen treatment, surgical ovariectomy or finasteride treatment all attenuated AR expression in ocular tissues. These observations suggested that androgen deficiency contributes to tear deficiency and may provide a biochemical mechanism to delineate the role of androgen deficiency on tear film structural and functional integrity in humans. Androgen deficiency is, therefore, a critical etiological factor in the pathogenesis of meibomian gland dysfunction and evaporative dry eye disease. Androgen deficiency caused disruption of all three layers of tear film production as demonstrated by the changes in tear production, TBUT, and corneal epithelial ultrastructure [88].

Lapi et al [89] reported that in a large case-control study on over 10,000 men with prostate cancer ADT increased risk of acute kidney injury. Similarly, Shoskes et al [90] concluded that low $\mathrm{T}$ levels were associated with increased risk of graft loss in male kidney transplant recipients. Approximately 50\% to $70 \%$ of men with severe chronic kidney disease (CKD) were $\mathrm{T}$ deficient as assessed by total and free $\mathrm{T}$ levels [91,92]. In a recent study, with a median follow-up of 11 years, demonstrated that the HR of developing CKD men with low $\mathrm{T}$ was 1.26-fold (95\% CI=1.02-1.60) which was higher than in men with normal $\mathrm{T}$ levels. The findings were significant even after multiple adjustments for potential confounders related to CKD including age, BMI, smoking, dyslipidemia, diabetes, and hypertension (HR adjusted $=1.38$; 95\% $\mathrm{CI}=1.05-1.80$ ). In an animal model study, castration exacerbates albuminuria, glomerulosclerosis, and tubulointerstitial fibrosis associated with diabetic renal disease [93]. In streptozotocininduced diabetic rat animal model $5 \alpha$-DHT treatment for 14 weeks attenuated castration-associated increases in urine albumin excretion, glomerulosclerosis, tubulointerstitial fibrosis, collagen type IV, transforming growth factor-b, IL-6 and protein expression and reduced CD68-positive cell abundance [94].
Here we advance the concept that blockade of the $5 \alpha-\mathrm{R}$ enzymatic activities by such irreversible inhibitors results in a state of new form of androgen deficiency, independent of circulating $\mathrm{T}$ levels. This new form of androgen deficiency has not been recognized before, simply, it is thought that as long as $\mathrm{T}$ levels are in the physiological range, androgen sufficiency is considered normal. Because finasteride and dutasteride are often prescribed to treat LUTS in men with BPH and male pattern hair loss in men with AGA for prolonged periods of time, it is postulated that men treated with these drugs are in a state of androgen deficiency and are at high risk of developing NAFLD IR, T2DM, dry eye disease, potential kidney dysfunction, among other metabolic dysfunctions. For these reasons, we believe that the clinical community should recognize these new potential health risks associated with these drugs and we believe "it's time to sound the alarm" on these drugs.

\section{Conflict of interest}

The author has nothing to disclose.

\section{Author contribution}

Conceptualization: AMT. Data curation: AMT. Formal analysis: AMT. Writing-original draft: AMT. Writing-review \& editing: AMT.

\section{REFERENCES}

1. Traish AM, Melcangi RC, Bortolato M, Garcia-Segura LM, Zitzmann M. Adverse effects of $5 \alpha$-reductase inhibitors: What do we know, don't know, and need to know? Rev Endocr Metab Disord 2015;16:177-98.

2. Traish AM. The post-finasteride syndrome: clinical manifestation of drug-induced epigenetics due to endocrine disruption. Curr Sex Health Rep 2018;10:88-103.

3. Traish AM. 5a-reductases in human physiology: an unfolding story. Endocr Pract 2012;18:965-75.

4. Traish AM, Guay AT, Zitzmann M. 5a-Reductase inhibitors alter steroid metabolism and may contribute to insulin resistance, diabetes, metabolic syndrome and vascular disease: a medical hypothesis. Horm Mol Biol Clin Investig 2014;20:7380.

5. Traish AM. Negative impact of testosterone deficiency and $5 a$-reductase inhibitors therapy on metabolic and sexual 
function in men. Adv Exp Med Biol 2017;1043:473-526.

6. Traish A, Haider KS, Doros G, Haider A. Long-term dutasteride therapy in men with benign prostatic hyperplasia alters glucose and lipid profiles and increases severity of erectile dysfunction. Horm Mol Biol Clin Investig 2017;30. doi: 10.1515/hmbci-2017-0015.

7. Traish AM. Post-finasteride syndrome: a surmountable challenge for clinicians. Fertil Steril 2020;113:21-50.

8. Bull HG, Garcia-Calvo M, Andersson S, Baginsky WF, Chan HK, Ellsworth DE, et al. Mechanism-based inhibition of human steroid $5 a$-reductase by finasteride: enzyme-catalyzed formation of NADP-dihydrofinasteride, a potent bisubstrate analog inhibitor. J Am Chem Soc 1996;118:2359-2365.

9. Belknap SM, Aslam I, Kiguradze T, Temps WH, Yarnold PR, Cashy J, et al. Adverse event reporting in clinical trials of finasteride for androgenic alopecia: a meta-analysis. JAMA Dermatol 2015;151:600-6.

10. Kiguradze T, Temps WH, Yarnold PR, Cashy J, Brannigan RE, Nardone B, et al. Persistent erectile dysfunction in men exposed to the $5 a$-reductase inhibitors, finasteride, or dutasteride. PeerJ 2017;5:e3020.

11. Nasiri M, Nikolaou N, Parajes S, Krone NP, Valsamakis G, Mastorakos G, et al. 5a-reductase type 2 regulates glucocorticoid action and metabolic phenotype in human hepatocytes. Endocrinology 2015;156:2863-71.

12. Hazlehurst JM, Oprescu AI, Nikolaou N, Di Guida R, Grinbergs AE, Davies NP, et al. Dual-5 $\alpha$-reductase inhibition promotes hepatic lipid accumulation in man. J Clin Endocrinol Metab 2016;101:103-13.

13. Livingstone DE, Barat P, Di Rollo EM, Rees GA, Weldin BA, Rog-Zielinska EA, et al. 5a-Reductase type 1 deficiency or inhibition predisposes to insulin resistance, hepatic steatosis, and liver fibrosis in rodents. Diabetes 2015;64:447-58.

14. Dowman JK, Hopkins LJ, Reynolds GM, Armstrong MJ, Nasiri M, Nikolaou N, et al. Loss of $5 a$-reductase type 1 accelerates the development of hepatic steatosis but protects against hepatocellular carcinoma in male mice. Endocrinology 2013;154:4536-47.

15. Mak TCS, Livingstone DEW, Nixon M, Walker BR, Andrew R. Role of hepatic glucocorticoid receptor in metabolism in models of $5 \alpha \mathrm{R} 1$ deficiency in male mice. Endocrinology 2019;160:2061-73.

16. Upreti R, Hughes KA, Livingstone DE, Gray CD, Minns FC, Macfarlane DP, et al. 5a-reductase type 1 modulates insulin sensitivity in men. J Clin Endocrinol Metab 2014;99:E1397406.

17. Wei L, Lai EC, Kao-Yang YH, Walker BR, MacDonald TM, Andrew R. Incidence of type 2 diabetes mellitus in men re- ceiving steroid $5 a$-reductase inhibitors: population based cohort study. BMJ 2019;365:11204.

18. Baig MS, Kolasa-Wołosiuk A, Pilutin A, Safranow K, Baranowska-Bosiacka I, Kabat-Koperska J, et al. Finasteride-induced inhibition of $5 \alpha$-reductase type 2 could lead to kidney damage-animal, experimental study. Int J Environ Res Public Health 2019;16:E1726.

19. Zhang C, Li K, Yang Z, Wang Y, Si H. The effect of the aqueous extract of Bidens pilosa L. on androgen deficiency dry eye in rats. Cell Physiol Biochem 2016;39:266-77.

20. Singh S, Moksha L, Sharma N, Titiyal JS, Biswas NR, Velpandian T. Development and evaluation of animal models for sex steroid deficient dry eye. J Pharmacol Toxicol Methods 2014;70:29-34.

21. Morava E, Wevers RA, Cantagrel V, Hoefsloot LH, Al-Gazali L, Schoots J, et al. A novel cerebello-ocular syndrome with abnormal glycosylation due to abnormalities in dolichol metabolism. Brain 2010;133:3210-20.

22. Taylor RL, Arno G, Poulter JA, Khan KN, Morarji J, Hull S, et al.; UK Inherited Retinal Disease Consortium and the 100,000 Genomes Project. Association of steroid 5a-reductase type 3 congenital disorder of glycosylation with early-onset retinal dystrophy. JAMA Ophthalmol 2017;135:339-47.

23. Li K, Zhang C, Yang Z, Wang Y, Si H. Evaluation of a novel dry eye model induced by oral administration of finasteride. Mol Med Rep 2017;16:8763-70.

24. Zhang H, Liu Y, Wang L, Li Z, Zhang H, Wu J, et al. Differential effects of estrogen/androgen on the prevention of nonalcoholic fatty liver disease in the male rat. J Lipid Res 2013;54:345-57.

25. Westerbacka J, Yki-Järvinen H, Vehkavaara S, Häkkinen AM, Andrew R, Wake DJ, et al. Body fat distribution and cortisol metabolism in healthy men: enhanced 5beta-reductase and lower cortisol/cortisone metabolite ratios in men with fatty liver. J Clin Endocrinol Metab 2003;88:4924-31.

26. Lee SS, Yang YW, Tsai TH, Kuo YH, Chuang HY, Lee CC, et al. 5-alpha-reductase inhibitors and the risk of diabetes mellitus: a nationwide population-based study. Prostate 2016;76:41-7.

27. Sullivan DA, Rocha EM, Aragona P, Clayton JA, Ding J, Golebiowski $B$, et al. TFOS DEWS II sex, gender, and hormones report. Ocul Surf 2017;15:284-333.

28. Sullivan BD, Evans JE, Cermak JM, Krenzer KL, Dana MR, Sullivan DA. Complete androgen insensitivity syndrome: effect on human meibomian gland secretions. Arch Ophthalmol 2002;120:1689-99.

29. Sullivan DA, Allansmith MR. Hormonal modulation of tear volume in the rat. Exp Eye Res 1986;42:131-9. 
30. Sullivan DA, Krenzer KL, Sullivan BD, Tolls DB, Toda I, Dana MR. Does androgen insufficiency cause lacrimal gland inflammation and aqueous tear deficiency? Invest Ophthalmol Vis Sci 1999;40:1261-5.

31. Sullivan DA. Tearful relationships? Sex, hormones, the lacrimal gland, and aqueous-deficient dry eye. Ocul Surf 2004;2:92-123.

32. Sullivan BD, Evans JE, Dana MR, Sullivan DA. Impact of androgen deficiency on the lipid profiles in human meibomian gland secretions. Adv Exp Med Biol 2002;506:449-58.

33. Cermak JM, Krenzer KL, Sullivan RM, Dana MR, Sullivan DA. Is complete androgen insensitivity syndrome associated with alterations in the meibomian gland and ocular surface? Cornea 2003;22:516-21.

34. Krenzer KL, Dana MR, Ullman MD, Cermak JM, Tolls DB, Evans JE, et al. Effect of androgen deficiency on the human meibomian gland and ocular surface. J Clin Endocrinol Metab 2000;85:4874-82.

35. Wilson EM, French FS. Binding properties of androgen receptors. Evidence for identical receptors in rat testis, epididymis, and prostate. J Biol Chem 1976;251:5620-9.

36. Lugg JA, Rajfer J, González-Cadavid NF. Dihydrotestosterone is the active androgen in the maintenance of nitric oxide-mediated penile erection in the rat. Endocrinology 1995;136:1495-501.

37. Gacci M, Ficarra V, Sebastianelli A, Corona G, Serni S, Shariat SF, et al. Impact of medical treatments for male lower urinary tract symptoms due to benign prostatic hyperplasia on ejaculatory function: a systematic review and meta-analysis. J Sex Med 2014;11:1554-66.

38. Liu L, Zhao S, Li F, Li E, Kang R, Luo L, et al. Effect of $5 a$-reductase inhibitors on sexual function: a meta-analysis and systematic review of randomized controlled trials. J Sex Med 2016;13:1297-310.

39. Corona G, Tirabassi G, Santi D, Maseroli E, Gacci M, Dicuio $\mathrm{M}$, et al. Sexual dysfunction in subjects treated with inhibitors of $5 \alpha$-reductase for benign prostatic hyperplasia: a comprehensive review and meta-analysis. Andrology 2017;5:671-8.

40. Pinsky MR, Gur S, Tracey AJ, Harbin A, Hellstrom WJ. The effects of chronic 5-alpha-reductase inhibitor (dutasteride) treatment on rat erectile function. J Sex Med 2011;8:3066-74.

41. Zhang MG, Wang XJ, Shen ZJ, Gao PJ. Long-term oral administration of $5 \alpha$-reductase inhibitor attenuates erectile function by inhibiting autophagy and promoting apoptosis of smooth muscle cells in corpus cavernosum of aged rats. Urology 2013;82:743.e9-15.

42. Oztekin CV, Gur S, Abdulkadir NA, Lokman U, Akdemir AÖ, Cetinkaya $\mathrm{M}$, et al. Incomplete recovery of erectile function in rat after discontinuation of dual 5-alpha reductase inhibitor therapy. J Sex Med 2012;9:1773-81.

43. Enatsu N, Chiba K, Sumii K, Fukuda T, Okada K, Matsushita $\mathrm{K}$, et al. Dutasteride-mediated morphological changes in the genitourinary tract associated with altered expression patterns of the androgen and estrogen receptors in male rats. Andrology 2017;5:347-53.

44. Kang HJ, Imperato-McGinley J, Zhu YS, Rosenwaks Z. The effect of $5 \alpha$-reductase- 2 deficiency on human fertility. Fertil Steril 2014;101:310-6.

45. Wang RS, Yeh S, Tzeng CR, Chang C. Androgen receptor roles in spermatogenesis and fertility: lessons from testicular cell-specific androgen receptor knockout mice. Endocr Rev 2009;30:119-32.

46. Huhtaniemi I. Mechanisms in endocrinology: hormonal regulation of spermatogenesis: mutant mice challenging old paradigms. Eur J Endocrinol 2018;179:R143-50.

47. Mendonca BB, Batista RL, Domenice S, Costa EM, Arnhold IJ, Russell DW, et al. Steroid 5a-reductase 2 deficiency. J Steroid Biochem Mol Biol 2016;163:206-11.

48. Dallob AL, Sadick NS, Unger W, Lipert S, Geissler LA, Gregoire SL, et al. The effect of finasteride, a 5 alpha-reductase inhibitor, on scalp skin testosterone and dihydrotestosterone concentrations in patients with male pattern baldness. J Clin Endocrinol Metab 1994;79:703-6.

49. Kwack MH, Sung YK, Chung EJ, Im SU, Ahn JS, Kim MK, Kim JC. Dihydrotestosterone-inducible dickkopf 1 from balding dermal papilla cells causes apoptosis in follicular keratinocytes. J Invest Dermatol 2008;128:262-9.

50. Urysiak-Czubatka I, Kmieć ML, Broniarczyk-Dyła G. Assessment of the usefulness of dihydrotestosterone in the diagnostics of patients with androgenetic alopecia. Postepy Dermatol Alergol 2014;31:207-15.

51. Adil A, Godwin M. The effectiveness of treatments for androgenetic alopecia: a systematic review and meta-analysis. J Am Acad Dermatol 2017;77:136-41.e5.

52. Gupta AK, Charrette A. The efficacy and safety of $5 a$-reductase inhibitors in androgenetic alopecia: a network meta-analysis and benefit-risk assessment of finasteride and dutasteride. J Dermatolog Treat 2014;25:156-61.

53. Navarro G, Xu W, Jacobson DA, Wicksteed B, Allard C, Zhang G, et al. Extranuclear actions of the androgen receptor enhance glucose-stimulated insulin secretion in the male. Cell Metab 2016;23:837-51.

54. Mauvais-Jarvis F. Androgen-deprivation therapy and pancreatic $\beta$-cell dysfunction in men. J Diabetes Complications 2016;30:389-90.

55. Azzolina B, Ellsworth K, Andersson S, Geissler W, Bull HG, 
Harris GS. Inhibition of rat alpha-reductases by finasteride: evidence for isozyme differences in the mechanism of inhibition. J Steroid Biochem Mol Biol 1997;61:55-64.

56. Ellsworth KP, Azzolina BA, Cimis G, Bull HG, Harris GS. Cloning, expression and characterization of rhesus macaque types 1 and 2 5alpha-reductase: evidence for mechanismbased inhibition by finasteride. J Steroid Biochem Mol Biol 1998;66:271-9.

57. Tian G, Stuart JD, Moss ML, Domanico PL, Bramson HN, Patel IR, et al. 17 beta-(N-tert-butylcarbamoyl)-4-aza-5 alphaandrostan-1-en-3-one is an active site-directed slow timedependent inhibitor of human steroid 5 alpha-reductase 1 . Biochemistry 1994;33:2291-6.

58. Gild P, Cole AP, Krasnova A, Dickerman BA, von Landenberg $\mathrm{N}$, Sun $\mathrm{M}$, et al. Liver disease in men undergoing androgen deprivation therapy for prostate cancer. J Urol 2018;200:57381.

59. Kim S, Kwon H, Park JH, Cho B, Kim D, Oh SW, et al. A low level of serum total testosterone is independently associated with nonalcoholic fatty liver disease. BMC Gastroenterol 2012;12:69.

60. Miyauchi S, Miyake T, Miyazaki M, Eguchi T, Niiya T, Yamamoto $\mathrm{S}$, et al. Free testosterone concentration is inversely associated with markers of liver fibrosis in men with type 2 diabetes mellitus. Endocr J 2017;64:1137-42.

61. Shen M, Shi H. Sex hormones and their receptors regulate liver energy homeostasis. Int J Endocrinol 2015;2015:294278.

62. Jacqueson A, Thevenin M, Warnet JM, Claude JR, Truhaut R. Comparative study of the protective effect of an anabolic steroid. The 19-nortestosterone-phenylpropionate (19 NTPP), on liver steatosis induced by Amanita phalloides and white phosphorus in rats. Arch Toxicol Suppl 1978;(1):193-6.

63. Saint-Aubert B, Vic P, Brissac C, Bories P, Humeau C, Joyeux $\mathrm{H}$, et al. [Hepatic regeneration in the rat after subtotal (90\%) hepatectomy treated with testosterone]. C R Seances Acad Sci D 1980;291:653-5. French.

64. Hazlehurst JM, Tomlinson JW. Non-alcoholic fatty liver disease in common endocrine disorders. Eur J Endocrinol 2013;169:R27-37.

65. Völzke H, Aumann N, Krebs A, Nauck M, Steveling A, Lerch $\mathrm{MM}$, et al. Hepatic steatosis is associated with low serum testosterone and high serum DHEAS levels in men. Int J Androl 2010;33:45-53.

66. Kelly DM, Nettleship JE, Akhtar S, Muraleedharan V, Sellers DJ, Brooke JC, et al. Testosterone suppresses the expression of regulatory enzymes of fatty acid synthesis and protects against hepatic steatosis in cholesterol-fed androgen deficient mice. Life Sci 2014;109:95-103.
67. Lin HY, Yu IC, Wang RS, Chen YT, Liu NC, Altuwaijri S, et al. Increased hepatic steatosis and insulin resistance in mice lacking hepatic androgen receptor. Hepatology 2008;47:192435

68. Lin HY, Xu Q, Yeh S, Wang RS, Sparks JD, Chang C. Insulin and leptin resistance with hyperleptinemia in mice lacking androgen receptor. Diabetes 2005;54:1717-25.

69. Sakr HF, Hussein AM, Eid EA, AlKhateeb M. Possible mechanisms underlying fatty liver in a rat model of male hypogonadism: a protective role for testosterone. Steroids 2018;135:21-30.

70. Zitzmann M. Testosterone deficiency, insulin resistance and the metabolic syndrome. Nat Rev Endocrinol 2009;5:673-81.

71. Traish AM, Saad F, Guay A. The dark side of testosterone deficiency: II. Type 2 diabetes and insulin resistance. J Androl 2009;30:23-32.

72. Keating NL, O'Malley A, Freedland SJ, Smith MR. Diabetes and cardiovascular disease during androgen deprivation therapy: observational study of veterans with prostate cancer. J Natl Cancer Inst 2012;104:1518-23.

73. Morimoto S, Fernandez-Mejia C, Romero-Navarro G, Morales-Peza N, Díaz-Sánchez V. Testosterone effect on insulin content, messenger ribonucleic acid levels, promoter activity, and secretion in the rat. Endocrinology 2001;142:1442-7.

74. Morimoto S, Mendoza-Rodríguez CA, Hiriart M, Larrieta ME, Vital P, Cerbón MA. Protective effect of testosterone on early apoptotic damage induced by streptozotocin in rat pancreas. J Endocrinol 2005;187:217-24.

75. Traish AM, Abdallah B, Yu G. Androgen deficiency and mitochondrial dysfunction: implications for fatigue, muscle dysfunction, insulin resistance, diabetes, and cardiovascular disease. Horm Mol Biol Clin Investig 2011;8:431-44.

76. Yialamas MA, Dwyer AA, Hanley E, Lee H, Pitteloud N, Hayes FJ. Acute sex steroid withdrawal reduces insulin sensitivity in healthy men with idiopathic hypogonadotropic hypogonadism. J Clin Endocrinol Metab 2007;92:4254-9.

77. Pitteloud N, Mootha VK, Dwyer AA, Hardin M, Lee H, Eriksson KF, et al. Relationship between testosterone levels, insulin sensitivity, and mitochondrial function in men. Diabetes Care 2005;28:1636-42.

78. Pitteloud N, Hardin M, Dwyer AA, Valassi E, Yialamas M, Elahi D, et al. Increasing insulin resistance is associated with a decrease in Leydig cell testosterone secretion in men. J Clin Endocrinol Metab 2005;90:2636-41.

79. Mantelli F, Moretti C, Macchi I, Massaro-Giordano G, Cozzupoli GM, Lambiase A, et al. Effects of sex hormones on ocular surface epithelia: lessons learned from polycystic ovary syndrome. J Cell Physiol 2016;231:971-5. 
80. el-Hage SG, Beaulne C. Changes in central and peripheral corneal thickness with menstrual cycle. Am J Optom Arch Am Acad Optom 1973;50:863-71.

81. Beauregard C, Brandt P. Down regulation of interleukin-1beta-induced nitric oxide production in lacrimal gland acinar cells by sex steroids. Curr Eye Res 2004;29:59-66.

82. Schirra F, Suzuki T, Richards SM, Jensen RV, Liu M, Lombardi MJ, et al. Androgen control of gene expression in the mouse meibomian gland. Invest Ophthalmol Vis Sci 2005;46:366675.

83. Argüeso P, Guzman-Aranguez A, Mantelli F, Cao Z, Ricciuto J, Panjwani N. Association of cell surface mucins with galectin-3 contributes to the ocular surface epithelial barrier. J Biol Chem 2009;284:23037-45.

84. Govindarajan B, Gipson IK. Membrane-tethered mucins have multiple functions on the ocular surface. Exp Eye Res 2010;90:655-63.

85. Mantelli F, Moretti C, Micera A, Bonini S. Conjunctival mucin deficiency in complete androgen insensitivity syndrome (CAIS). Graefes Arch Clin Exp Ophthalmol 2007;245:899902.

86. Mantelli F, Argüeso P. Functions of ocular surface mucins in health and disease. Curr Opin Allergy Clin Immunol 2008;8:477-83.

87. Qin L, Pei C, Kang QY, Liu Z, Li L. Effect of dihydrotestosterone on the expression of mucin 1 and the activity of Wnt signaling in mouse corneal epithelial cells. Int J Ophthalmol 2016;9:1535-40.

88. Li L, Kang Q, Wang S, Zheng X. Effects of androgen on ultrastructure of corneal epithelium and function of the tear film in BALB/c mice. Cornea 2015;34:334-41.

89. Lapi F, Azoulay L, Niazi MT, Yin H, Benayoun S, Suissa S. Androgen deprivation therapy and risk of acute kidney injury in patients with prostate cancer. JAMA 2013;310:289-96.

90. Shoskes DA, Kerr H, Askar M, Goldfarb DA, Schold J. Low testosterone at time of transplantation is independently associated with poor patient and graft survival in male renal transplant recipients. J Urol 2014;192:1168-71.

91. Albaaj F, Sivalingham M, Haynes P, McKinnon G, Foley RN, Waldek S, et al. Prevalence of hypogonadism in male patients with renal failure. Postgrad Med J 2006;82:693-6.

92. Gómez F, de la Cueva R, Wauters JP, Lemarchand-Béraud T. Endocrine abnormalities in patients undergoing long-term hemodialysis. The role of prolactin. Am J Med 1980;68:52230.

93. Xu Q, Wells CC, Garman JH, Asico L, Escano CS, Maric C. Imbalance in sex hormone levels exacerbates diabetic renal disease. Hypertension 2008;51:1218-24.

94. Xu Q, Prabhu A, Xu S, Manigrasso MB, Maric C. Dose-dependent effects of dihydrotestosterone in the streptozotocininduced diabetic rat kidney. Am J Physiol Renal Physiol 2009;297:F307-15. 